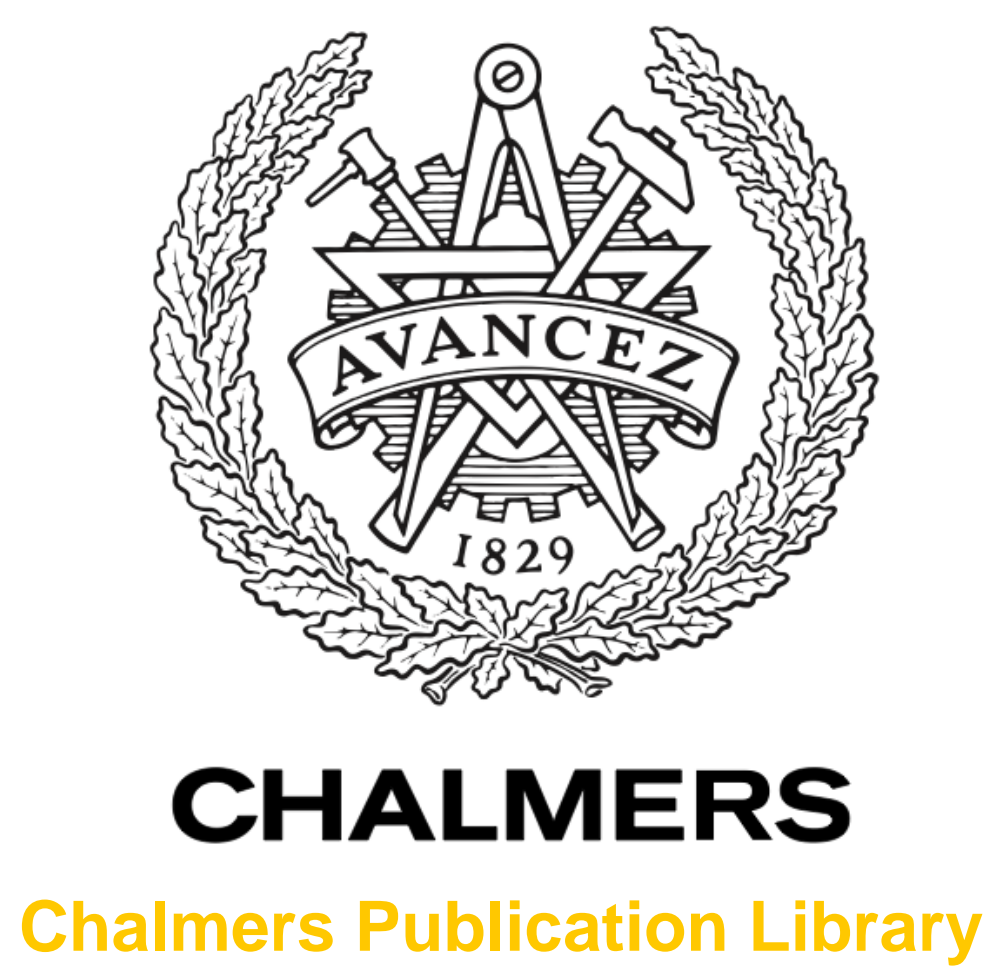

\title{
Targeting for energy efficiency and improved energy collaboration between different companies using total site analysis (TSA)
}

This document has been downloaded from Chalmers Publication Library (CPL). It is the author's version of a work that was accepted for publication in:

\section{Energy (ISSN: 0360-5442)}

Citation for the published paper:

Hackl, R. ; Andersson, E. ; Harvey, S. (2011) "Targeting for energy efficiency and improved energy collaboration between different companies using total site analysis (TSA)". Energy, vol. 36(8), pp. 4609-4615.

Downloaded from: http://publications.lib.chalmers.se/publication/145658

Notice: Changes introduced as a result of publishing processes such as copy-editing and formatting may not be reflected in this document. For a definitive version of this work, please refer to the published source. Please note that access to the published version might require a subscription. 


\title{
Targeting for energy efficiency and improved energy collaboration between different companies using total site analysis (TSA)
}

\author{
Roman Hackl $^{\mathrm{a},{ }^{*}, \text { Eva Andersson }}{ }^{\mathrm{b}}$, Simon Harvey ${ }^{\mathrm{a}}$ \\ ${ }^{a}$ Division of Heat and Power Technology, Department of Energy and Environment, Chalmers University of Technology, \\ Kemivägen 4, SE-412 96 Gothenburg, Sweden \\ ${ }^{b}$ CIT Industriell Energi, Chalmers Science Park, SE-412 96 Gothenburg, Sweden \\ "Corresponding author: Tel: +4631 772 3861, Fax: +4631 821928, E-mail: roman.hackl@chalmers.se
}

\begin{abstract}
Rising fuel prices, increasing costs associated with emissions of green house gases and the threat of global warming make efficient use of energy more and more important. Industrial clusters have the potential to significantly increase energy efficiency by energy collaboration. In this paper Sweden's largest chemical cluster is analysed using the Total Site Analysis (TSA) method. TSA delivers targets for the amount of utility consumed and generated through excess energy recovery by the different processes. The method enables investigation of opportunities to deliver waste heat from one process to another using a common utility system.

The cluster consists of 5 chemical companies producing a variety of products, including polyethylene (PE), polyvinylchloride (PVC), amines, ethylene, oxygen/nitrogen and plasticisers. The companies already work together by exchanging material streams. In this study the potential for energy collaboration is analysed in order to reach an industrial symbiosis. The overall heating and cooling demands of the site are around 442 MW and $953 \mathrm{MW}$, respectively. $122 \mathrm{MW}$ of heat are produced in boilers and delivered to the processes. TSA is used to stepwise design a site-wide utility system which improves energy efficiency. It is shown that heat recovery in the cluster can be increased by $129 \mathrm{MW}$, i. e. the current utitlity demand could be completely eliminated and further $7 \mathrm{MW}$ excess steam can be made available. The proposed retrofitted utility system involves the introduction of a site-wide hot water circuit, increased recovery of low pressure steam and shifting of heating steam pressure to lower levels in a number heat exchangers when possible. Qualitative evaluation of the suggested measures shows that $60 \mathrm{MW}$ of the savings potential could to be achieved with moderate changes to the process utility system corresponding to $50 \%$ of the heat produced from purchased fuel in the boilers of the cluster.

Further analysis showed that after implementation of the suggested energy efficiency measures there is still a large excess of heat at temperatures of up to $137^{\circ} \mathrm{C}$.
\end{abstract}

Keywords: Total Site Analysis (TSA); industrial cluster; total site integration; utility system; pinch technology 


\begin{tabular}{|ll|}
\hline Nomenclature & \\
bar(g) & Bar gauge \\
CC & Composite Curves \\
CW & Cooling Water \\
GCC & Grand Composite Curve \\
HP & High Pressure (steam) \\
IP & Intermediate Pressure (Steam) \\
LP & Low Pressure (steam) \\
MP & Medium Pressure (steam) \\
ORC & Organic Rankie Cycle \\
PE & Polyethylene \\
PVC & Polyvinyl Chloride \\
$Q_{\text {cooling }}$ & Process cooling demand \\
$Q_{\text {consumed }}$ & Utility used for process heating \\
$Q_{\text {generated }}$ & Utility recovered from the process \\
$Q_{\text {heating }}$ & Process heating demand \\
$Q_{\text {rec }}$ & Recovered process heat \\
TSA & Total Site Analysis \\
TSC & Total Site Composites \\
TSP & Total Site Profiles \\
$T_{\text {start }}$ & Steam starting temperature \\
$T_{\text {target }}$ & Stream target temperature \\
$\Delta T_{\text {min }}$ & Minimum temperature difference \\
\hline
\end{tabular}

\section{Introduction}

\subsection{Background}

Site-wide process integration studies within industrial clusters often show large potential for energy savings, on average 20-25\% compared to the current energy usage of the total site [1]. Even highly efficient single plants can further improve their energy efficiency by sharing energy with other plants within a cluster [2]. Total Site Analysis (TSA) provides targets for the net amount of utility that is required for the site and the amount that can be produced through energy recovery by the different site processes. The method enables investigation of opportunities to deliver waste heat from one process to another using a common utility system and can also provide the basis for heat integration within a larger geographical area, which in addition to the industrial sites also includes building complexes, offices and residences [3].

In the presented work TSA is first applied in Sweden to a chemical cluster. The different plants are locally concentrated but their utility systems are only connected minimal. Former research focused on sites were a common utility system is already in place. As in the presented study this is not the case, therefore additional difficulties can arise. Different investment strategies and goals of the collaborating companies can influence the decision process. Also a general reluctance to become more dependent on each other when the plants are more connected can make common energy efficiency investments more complicated. These issues can be overcome by e.g. including an additional company in the process which is responsible for the operation of the common utility systems.

In this study the goal is to find pratical ways to build a more interconnected utility system which enables for heat integration throughout the whole cluster in order to decrease resource consumption and achieve an industrial symbiosis, where companies cooperate by exchanging material and energy flows [4].

\subsection{The chemical cluster in Stenungsund}

The chemical cluster investigated in this paper is located in Stenungsund on the West Coast of Sweden, and is Sweden's largest agglomeration of its kind. The companies involved and their main products are AGA Gas AB producing industrial gases, Akzo Nobel Sverige AB producing amines and surfactants, Borealis AB producing ethylene and polyethylene (PE), INEOS Sverige AB producing polyvinyl chloride (PVC) and Perstorp Oxo AB producing speciality chemicals. The companies have recently announced a common vision 
called "Sustainable Chemistry 2030" with the intention to increased collaboration for energy savings, increased use of renewable resources and decreased overall emissions. The heart of the cluster is a steam cracker plant run by Borealis, which delivers both feedstock and fuel gas to the other plants.

In total, 360 process streams, requiring utility heating and cooling were included in this study. The data was collected from real time process data, process simulations, previous studies and qualified engineering assumptions. Each plant has its own utility system. Utility system connections between the different plants at the total site are currently minimal. In total, 13 steam levels (ranging from $85 \mathrm{bar}(\mathrm{g})$ to $1 \mathrm{bar}(\mathrm{g})$ ), 3 different hot water systems, hot oil and flue gas heating together with water, air and refrigerant cooling are operated within the cluster to supply the heating and cooling demand of the processes. Table 1 shows the utilities used for heat recovery and process heating, together with the corresponding heat loads. The net difference between total heat recovered and heat consumed corresponds to the amount of heat that has to be covered by external heat from the boilers (ca. $122 \mathrm{MW}$ ). Waste heat from Borealis and Perstorp is currently delivered to the local district heating system. The amount of fresh water consumed by the cluster is restricted and not allowed to increase with future site expansions.

The companies already interact strongly with each other in terms of material exchange and are currently interested in investigating the potential for energy integration throughout the chemical cluster in Stenungsund. The objective of this study was to conduct preliminary analysis of total site level energy efficiency opportunities using the TSA methodology.

Table 1

Utilities currently used for heat recovery and process heating

\begin{tabular}{|c|c|c|c|c|}
\hline Utility & $\begin{array}{c}\text { Temperature } \\
{\left[{ }^{\circ} \mathrm{C}\right]}\end{array}$ & $\begin{array}{l}Q_{\text {generated }} \\
{[\mathrm{MW}]^{1}}\end{array}$ & $\begin{array}{l}Q_{\text {consumed }} \\
{\text { [MW }]^{2}}^{2}\end{array}$ & $\begin{array}{c}Q_{\text {generated }^{-}} \\
Q_{\text {consumed }[\mathrm{MW}]}\end{array}$ \\
\hline Steam 85 bar(g) & 300 & 50.8 & 1 & 49.8 \\
\hline Steam 40 bar(g) & 250 & 42 & 43.2 & -1.2 \\
\hline Steam 28 bar(g) & 230 & & 6.3 & -6.3 \\
\hline Steam 20 bar(g) & 215 & 29 & 38.5 & -9.5 \\
\hline Steam 14 bar(g) & 200 & 15.2 & 12.7 & 2.5 \\
\hline Steam 10 bar(g) & 184 & 22.1 & 21 & 1.1 \\
\hline Steam 8.8 bar(g) & 178 & 27.3 & 91 & -63.7 \\
\hline Steam 7 bar(g) & 168 & & 15.3 & -15.3 \\
\hline Steam 6 bar(g) & 163 & & 14.2 & -14.2 \\
\hline Steam 4 bar(g) & 150 & 26.1 & 2.2 & 23.9 \\
\hline Steam 2.7 bar(g) & 140 & 13 & 4.7 & 8.3 \\
\hline Steam 2 bar(g) & 131 & 55.3 & 128.4 & -73.1 \\
\hline Steam 1 bar(g) & 119 & 0.6 & 8.4 & -7.8 \\
\hline Hot oil & 277 & & 1.9 & -1.9 \\
\hline Hot water & $160-50$ & 9 & 13.3 & -4.3 \\
\hline Flue gas & 1400 & & 10.4 & -10.4 \\
\hline Sum & & 290.4 & 412.5 & -122.1 \\
\hline
\end{tabular}

1Heat load generated from excess process heat

2Heat load consumed in process heaters

\subsection{Related work}

The concept of TSA was introduced by Dhole and Linnhoff (1993) [5] with the purpose of extending Pinch technology from analysis of integration opportunities in single processes to site-wide integration. This was followed by further development of the methodology by Raissi (1994) [6], Hu and Ahmad (1994) [7] and Klemes et al. (1997) [8] accounting for co-generation, site expansion, emissions and utilities optimisation. Marechal and Kalitventzeff (1998) introduced the use of mathematical programming techniques to minimize costs of energy supply at a total site level [9] and developed also (2003) a method to target for the utility system which also takes into account multi-period operation and thereby changing utility demands of different plants at a total site [10].

Recent work performed by Bandyopadhyay et al. (2010) [11] incorporates the concept of assisted heat transfer where pockets in the individual process GCCs are not removed in order to increase overall heat integration. 
The work of Varbanov and Klemes (2010) [12] extends the traditional heat integration approach in order to include using renewable energy sources with changing availability in a total sites' energy system. A recent paper by Fodor et al. (2010) [13] introduces an individual- $\Delta \mathrm{T}_{\min }$ approach accounting for changes in heat transfer characteristics for different processes.

A site wide heat integration study on a large industrial cluster performed lately by Matsuda et al. (2009) [2] shows that even highly efficient single plants can further improve their energy efficiency by total site integration.

A recent publication by Klemes et al. (2010) [14] presents an overview of the TSA method and its applications.

\section{Methodology}

\subsection{Total Site Analysis (TSA)}

TSA is used to integrate the individual heating and cooling demands of different processes at a total site. Excess heat from one process plant is transferred to a common utility (e.g. steam, hot water, hot oil) and then delivered to processes with a heat deficit by the common utility system. The TSA method enables the amounts of hot utility generated and used by the combined individual processes, the amount of heat recovery in a common hot utility system, the steam demand from the boilers and the cogeneration potential to be determined [3].

\subsection{Data collection approaches for the total site analysis of the chemical cluster}

Data collection for TSA studies is time consuming, therefore practitioners have defined different approaches that can be used for conducting studies at different levels of detail. These approaches are briefly discussed below. The necessary data for each process stream is the starting temperature $T_{\text {start }}$, target temperature $T_{\text {target }}$, the heating/cooling demand and the respective utility if the stream is currently heated/cold by utility.

\section{White box approach or Detailed Pinch}

Detailed stream data for all process heating and cooling demands for each plant is collected and thereafter complete Composite Curves (CC) and Grand Composite Curve (GCC) can be constructed for the total site, and the minimum hot and cold utility demands can be determined.

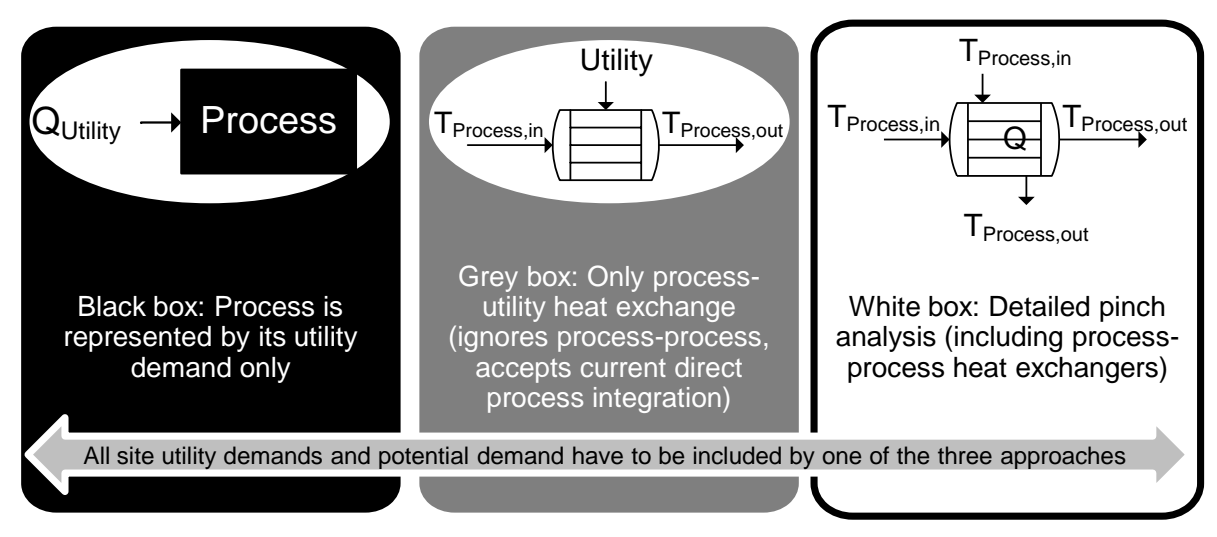

Figure 1: Illustration of the different data collection approaches in TSA

\section{Grey box approach:}

For each plant, only the process-utility interface is considered and process-process heat recovery is ignored. Only process streams which are heated/cooled by utilities are considered in the analysis based on their $T_{\text {start }}$, $T_{\text {target }}$ and heating/cooling loads. The current level of heat integration within each single plant is accepted as is, but the grey box approach enables to identify opportunities for transferring heat between plants.

\section{Black box approach:}

The process(-stream) is represented by data for the corresponding utility streams in heaters and coolers. Other utility users such as steam tracing or tank heating are often represented as black boxes [1]. Figure 1 illustrates the three approaches. It is important that all utility usage and potential demand is included in the study [15]. 
In this study most of the plants were handled using the "grey box" approach since opportunities for implementing energy efficiency measures in the individual plants have been identified in previous conducted studies, and the plants are therefore considered to be relatively energy efficient. The study was completed by a number of streams handled as "black box" so as to include utility consumers that are not included in the stream data gathered.

\subsection{Total Site Profiles and Total Site Composite Curves}

From the data collected the process source/sink profiles and the utility profiles can be plotted. In this study a minimum temperature difference $\left(\Delta T_{\min }\right)$ of $10 \mathrm{~K}$ between the process and utility streams was chosen. The so called Total Site Profiles (TSP) are obtained, see left-hand side in Figure 2. This enables to analyse how heat is supplied to and removed from the processes by different utilities. The site utility profiles are developed from process stream lists by representing the utilities used to cool/heat each process stream.

In order to find the maximum amount of heat recovery possible for the total site by heat exchange through the combined utility system, the total site profiles are moved towards each other until the hot and the cold utility curve intersect in one point, see Figure 2 to the right. This point is the so-called site pinch, which limits the amount of heat that can be recovered by the utility system. The overlapping curves in this figure are the so-called Total Site Composites (TSC). They show the minimum amount of heat that has to be supplied to the processes externally as hot utility $\left(Q_{\text {heating }}\right)$. This is illustrated in Figure 2. $Q_{\text {heating }}$ therefore directly relates to the boiler fuel requirement.

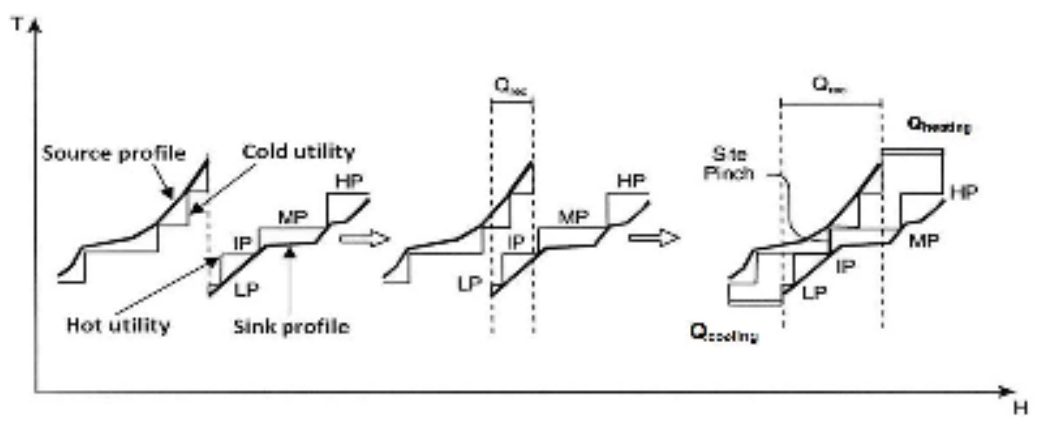

Figure 2: Total Site Profiles (TSP) and Total Site Composites (TSC) [7]

The cooling demand $\left(Q_{\text {cooling }}\right)$ in Figure 2 represents the amount of heat that has to be discharged from the processes. The TSP and TSC can be used to identify changes to the utility system that improve the total site heat integration through the utility system. Utility system changes are e.g. replacing steam by introducing a hot water circuit [16], introduction of new steam levels, steam generation from recovered process heat at higher levels or process stream heating with steam at lower level [7]. The curves can be used to target for fuel consumption and cogeneration [17].

\section{Results}

\subsection{Analysis of the current utility system}

Figure 3 and Figure 4 show TSP and TSC of the chemical cluster. The TSP represent cold and hot process streams (continuous lines), and cold and hot utility curves (dashed lines).

The total cooling demand of the processes is $953 \mathrm{MW}$. Currently $320 \mathrm{MW}$ heat is recovered from the processes, $281 \mathrm{MW}$ in form of steam. The total amount of process heat discharged to the environment by Cooling Water $(\mathrm{CW})$ and air is $556 \mathrm{MW}$. The rest of the cooling $(77 \mathrm{MW})$ is achieved by refrigeration. 


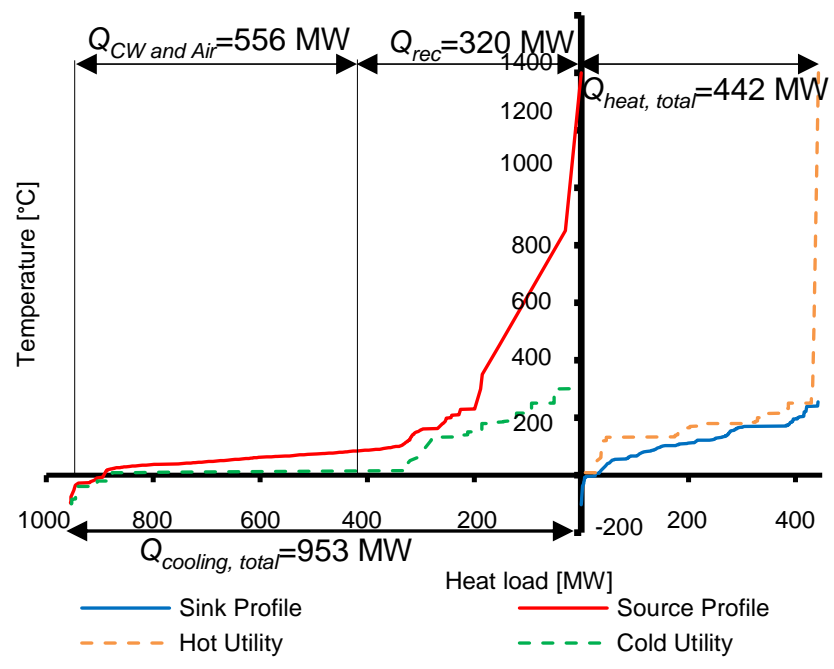

Figure 3: TSP of the chemical cluster in Stenungsund with its current utility system

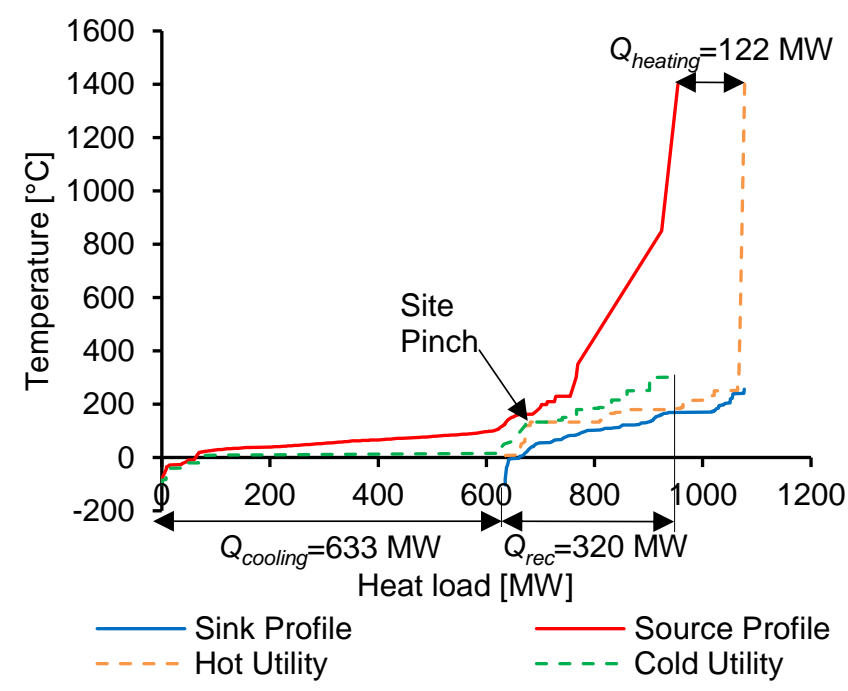

Figure 4: TSC of the chemical cluster in Stenungsund with its current utility system

The total heating demand is $442 \mathrm{MW}$ of which $388 \mathrm{MW}$ is covered by steam at different pressure levels, while $54 \mathrm{MW}$ is covered by hot water/oil, flue gases, steam condensate and refrigerant (to recover low temperature cooling energy).

As described previously the minimum heating requirement for the total site can be determined by overlapping the TSP curves to obtain the Total Site Composites and the site pinch, see Figure 2 (TSC to the right). The overlap of the source and the sink profiles (and the respective utility profiles) represents the potential amount of heat recovery by the utility system $(320 \mathrm{MW})$. The amount of heat that has to be produced by external fuel in boilers is $Q_{\text {heating }}=122 \mathrm{MW}$. 


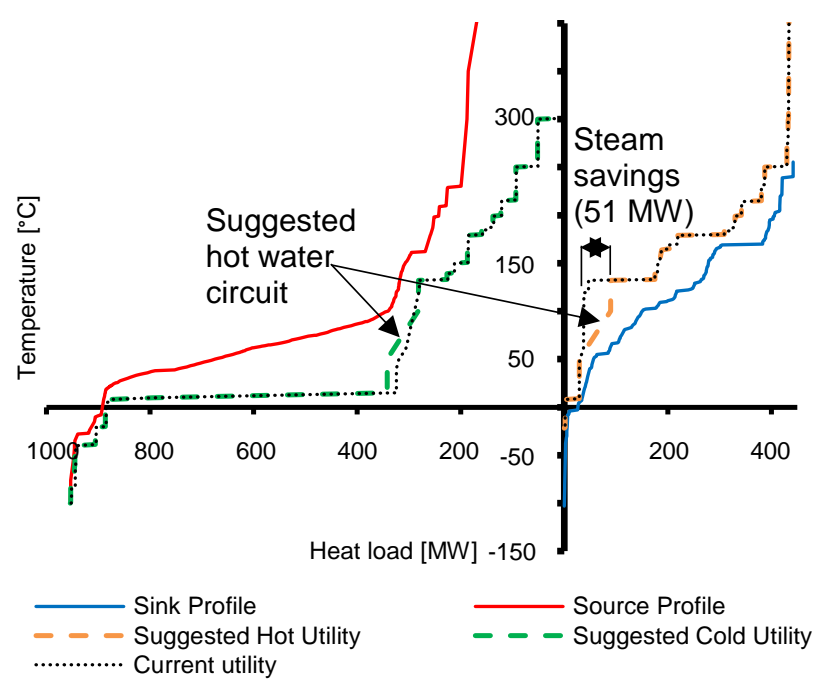

Figure 5: TSP after introduction of a new hot water heat recovery circuit

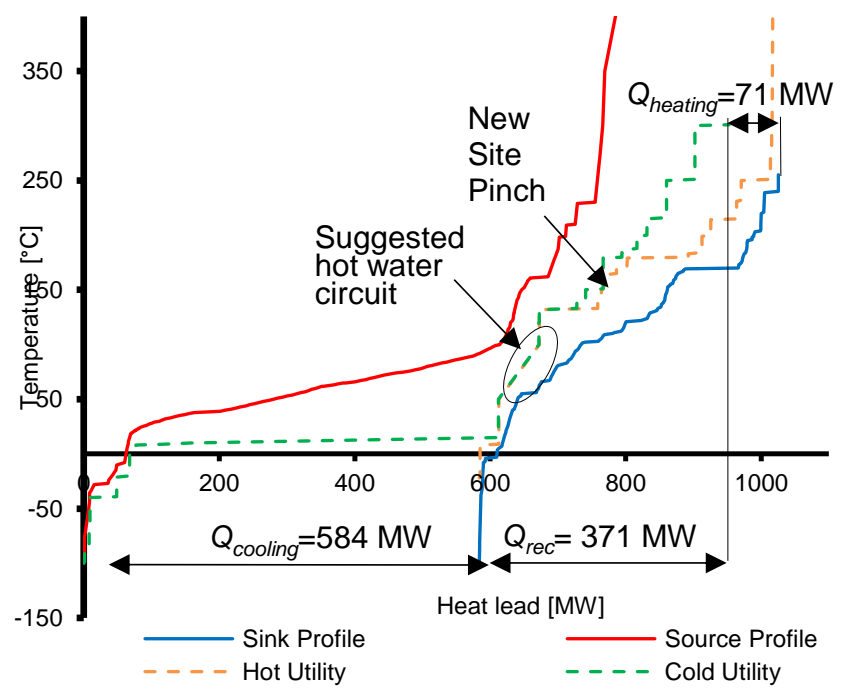

Figure 6: TSC after introduction of a new hot water heat recovery circuit

\subsection{Improvements to the total site utility system}

In this section the systematic procedure followed to increase site wide heat integration via a common utility system using TSP and TSC is presented:

- The TSC of the current utility system (Figure 4) show a large gap between the hot utility curve and the sink profile (especially for process temperatures below $100^{\circ} \mathrm{C}$ ).

$\rightarrow$ This leads to high exergy losses since the process streams are heated with utility at higher temperature than necessary.

- The source profile indicates that there is heat available (currently discharged) at suitable temperature to supply heat to the cold process streams. Heat from hot process streams can be recovered in the circulating hot water system and delivered to cold process streams (between 50 and $100^{\circ} \mathrm{C}$ ).

$\rightarrow$ Detailed analysis indicated that 2 bar(g) steam use for process heating could be replaced by hot water.

Implementation of such a circiut results in modified curves (see Figure 5 and Figure 6). The dashed lines in Figure 5 represent the new hot and cold utility profiles, while the dotted lines represent the current hot and cold utility profiles, with the resulting shift of the site pinch and increased overlap of the TSC. This can be seen when comparing $Q_{\text {heating }}$ in Figure 4 and Figure 6. Introducing a hot water circuit results in:

- Increased recovery of process heat to generate hot water between 50 and $100^{\circ} \mathrm{C}$

- Savings of $51 \mathrm{MW}$ steam at $2 \mathrm{bar}(\mathrm{g})$

A new site pinch is created, indicating that no further heat integration is possible. In Figure 6 it can be seen that there is still hot and cold process streams available, which are at a suitable temperature for heat recovery 
by a hot water circuit, but in practice the new site pinch implies that if more than $51 \mathrm{MW}$ of 2 bar(g) steam is replaced with hot water there will be an overall excess of 2 bar(g) steam. This is because there will still be the same amount of $2 \operatorname{bar}(\mathrm{g})$ steam recovered from process heat, but there is less demand since steam for heating purposes is replaced by hot water.

Further increase of heat recovery required further shifting of the site pinch. This can be achieved as follows:

- Necessary to shift the site pinch even further.

- Modify the operating conditions of certain heat exchangers. In this study we focused on heat exchangers not required thus steam at a higher level than 2 bar $(\mathrm{g})$ (see sink profile in Figure 6 ) $\rightarrow$ the steam level in these heat exchangers can be decreased $\rightarrow$ demand for $2 \operatorname{bar}(\mathrm{g})$ steam is increased.

- Proceed as above until another site pinch is created, which makes it necessary either to lower the steam level in heat exchangers using higher pressure steam or steam from excess process heat can be recovered at higher levels.

- Both measures make it possible to shift the site pinch and increase the overlap of the TSC.

- The TSC in Figure 4 also indicate the possiblility to increase generation of 2 bar(g) steam from recovered excess process heat (see Figure 7).

- The maximum theoretical heat integration is achieved, when $\Delta \mathrm{T}$ between source profile/cold utility and hot utility/sink profile approaches $\Delta T_{\min }\left(\right.$ here $\left.\Delta T_{\min }=10 \mathrm{~K}\right)$

The TSP corresponding to maximum energy recovery achieved by the measures described above are shown in Figure 7. The dotted lines show the current hot and cold utility profiles, while the dashed lines show the suggested utility system. The suggested measures are summarised in Table 2 . The overall savings amount to $129 \mathrm{MW}$. In the lower part of Table 2 measures which not directly save steam, but are necessary to realise the total savings.

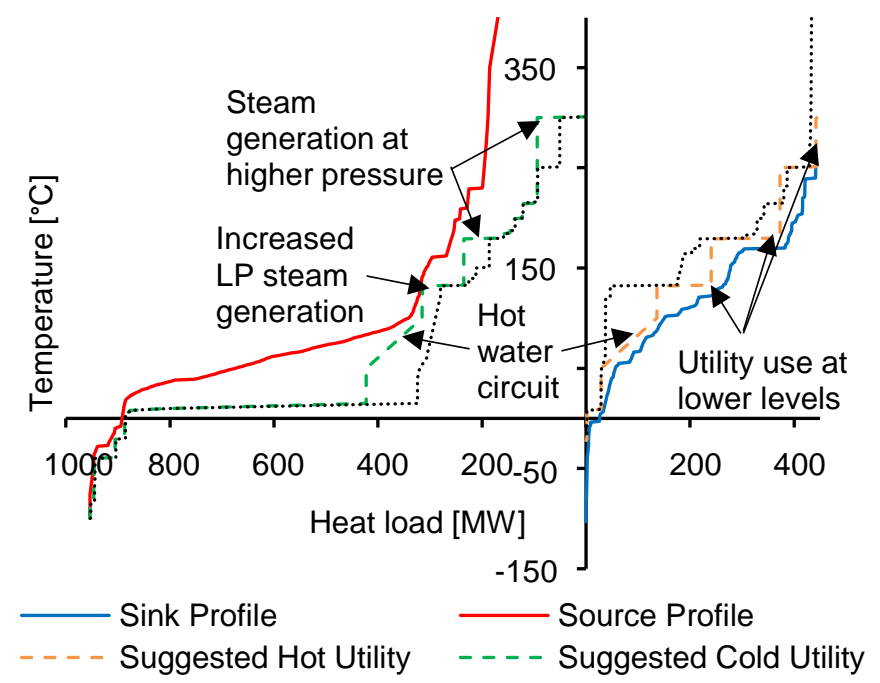

Figure 7: TSP after introduction of a utility system for maximum heat recovery 


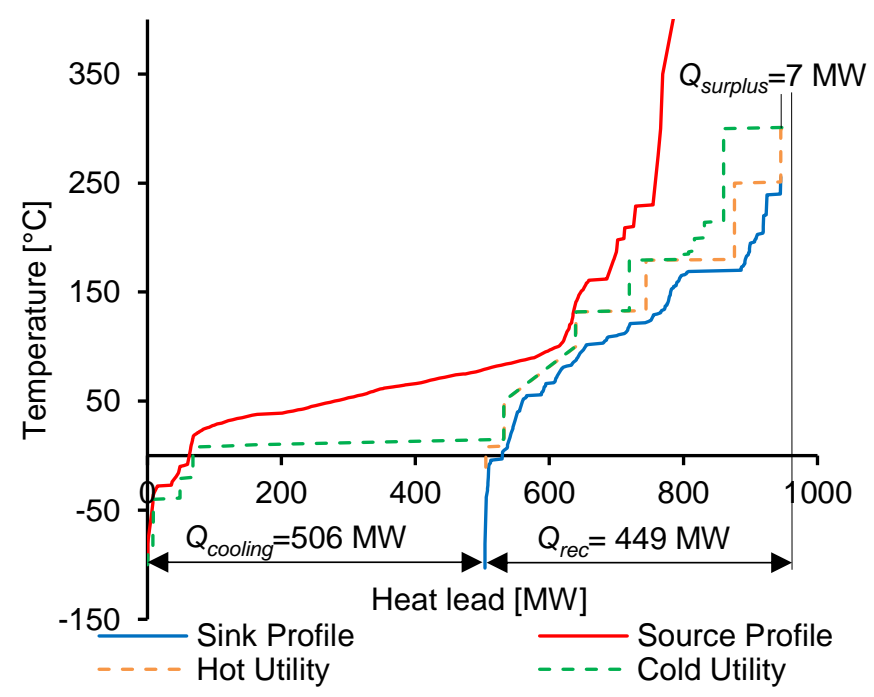

Figure 8: TSC after introduction of a utility system for maximum heat recovery

This implies that the site's current external utility demand of $122 \mathrm{MW}$ can in fact be completely covered by recovered process heat distributed by an interconnected utility system. Additionally 7 MW of excess steam would be available as illustrated by $Q_{\text {surplus }}$ in Figure 8 .

Table 2

Summary of measures to improve heat integration identified by TSA

\begin{tabular}{ll}
\hline Measure & Max. Savings and Comments \\
\hline $\begin{array}{l}\text { Introducing a circulating hot water } \\
\text { circuit between } 50 \text { and } 100^{\circ} \mathrm{C}\end{array}$ & $\begin{array}{l}\text { Saves } 96 \mathrm{MW} \text { of LP steam and } \\
\text { cooling demand }\end{array}$ \\
\hline Increase 2 bar(g) steam recovery & Increase 2 bar(g) steam by 33 MW \\
\hline Total Savings & $129 \mathrm{MW}$ \\
\hline $\begin{array}{l}\text { Increased } 8.8 \text { bar(g) steam recovery } \\
\text { by } 50 \mathrm{MW}\end{array}$ & $\begin{array}{l}\text { Necessary for further integration (to } \\
\text { cover } 8.8 \text { bar(g) demand) }\end{array}$ \\
\hline $\begin{array}{l}\text { Increased steam recovery at } 85 \text { bar }(\mathrm{g}) \\
\text { by } 44 \mathrm{MW}\end{array}$ & Necessary for further integration \\
\hline $\begin{array}{l}\text { Process heating with steam at lower } \\
\text { temperature levels by } 129 \mathrm{MW}\end{array}$ & $\begin{array}{l}\text { Necessary for further integration } \\
\text { (utilisation of recovered steam) }\end{array}$ \\
\hline Replace flue gas by steam by $10 \mathrm{MW}$ & Necessary for further integration \\
\hline
\end{tabular}

Qualitative evaluation of the suggested measures was conducted together with plant experts to assess their feasibility. The measures were sorted inte three categories:

- Possible, with moderate changes: Only the heat exchanger area has to be modified. No changes to other equipment is necessary. There is enough space available to conduct the modifications and no additional pipe racks are needed.

- Technically feasible: Beyond the heat exchangers also changes to other process equipment must be conducted, as there is e.g. a lack of space, additional pipe rack needs to be installed, heat exchangers are difficult to reach (top condensers, heat exchangers placed high above ground level etc.).

- Not feasible: The suggested measure is not possible for other process reasons.

This evaluation indicates that $60 \mathrm{MW}$ of the savings potential can be achieved with moderate changes and $110 \mathrm{MW}$ of savings are technically feasible without any process constraints.

\subsection{Potential use of residual excess process heat}

The amount of excess process heat available after maximum heat integration within the cluster via an improved utility system is illustrated in Figure 9. The GCC represents the heat transfer from the hot process streams to the utility systems. It contains the hot process and the utility demands for process heating of the improved system as presented in Figure 7 and Figure 8. This procedure enables to estimate the amount of heat available from the processes after the maximum amount of process heat is recovered via the common 
improved utility system. It can be seen that excess heat is available at higher temperature (7 MW) and at $137{ }^{\circ} \mathrm{C}$ and below. This means, that after maximum heat integration within the cluster there is still heat available for other use, e.g. between $137{ }^{\circ} \mathrm{C}$ and $50{ }^{\circ} \mathrm{C}$ there are $219 \mathrm{MW}$ of excess process heat available. Potential users of low temperature heat are:

- District heating

- Biomass drying

- Low temperature electricity production by e.g. an Organic Rankine Cycle (ORC)

Heat pumping of heat below $137{ }^{\circ} \mathrm{C}$ to higher temperature levels is not a viable option, as the heat demand above this temperature can be covered internally, as it can be seen in the GCC.

At the moment the district heating system of Stenungsund is small (ca. $10 \mathrm{MW}_{\text {heat }}$ ). Increasing interest in connecting the district heating systems of Stenungsund and the city of Gothenburg give enhanced incentives for utilization of excess process heat from the cluster.

In the cluster's future vision for a sustainable chemical industry in 2030 the increased utilization of biomass as a renewable resource to replace fossil feedstock plays an important role. Biomass generally contains a high amount of water which makes drying essential before it can be used as an energy or material resource. Technologies for biomass drying with low temperature heat exist and therefore excess heat from the cluster can be used for biomass drying purposes [18].

By ORC technology heat from low temperature sources is converted into electricity. Even if low temperature electricity production by e.g. ORC technology is characterized by low thermal efficiency it can be an interesting option in some cases [19], if e.g. the district heating system is satisfied and no other uses for waste heat exist.

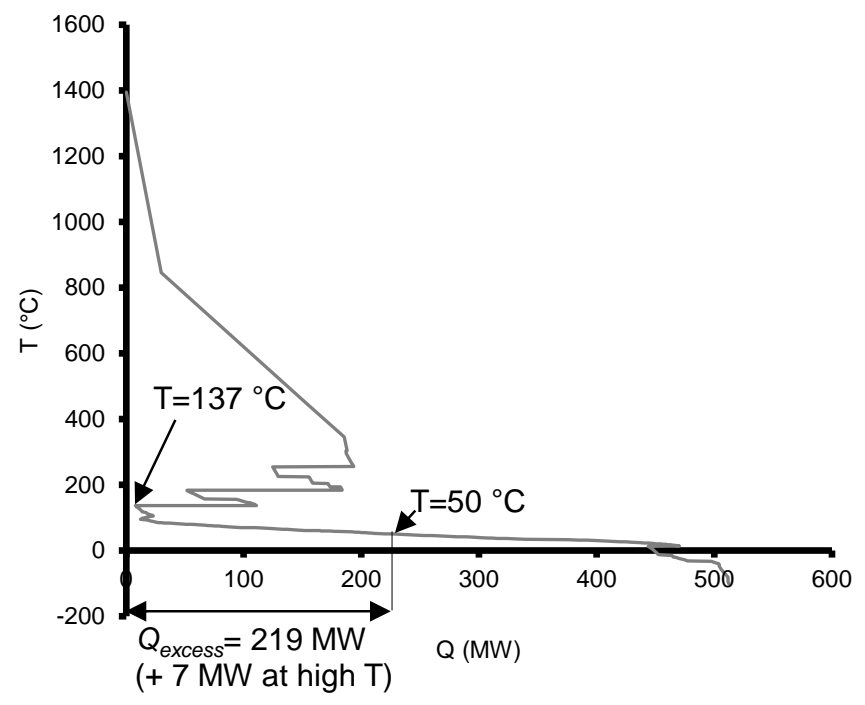

Figure 9: GCC representing the transfer of heat from hot process streams to an improved utility system to determine the amount of additional excess heat for alternative use

\subsection{Sources of error and uncertainty}

The total site curves used for implementing a site wide utility system and improving existing utilities area based average, steady state operation of the processes within the cluster. Therefore changes in loads and temperatures depending on e.g. the production rate, maintenance or the product changes are not considered. It is also assumed that all the processes are running simultaneously. Some processes analyzed are still in the commissioning phase and therefore design data is used for these processes. This does not necessarily reflect true operation conditions of the processes. Minor streams, which do not justify investment in process changes are only considered by the "black box"-approach meaning that only their utility consumption is considered (process temperature is set accordingly). Minor streams represent $15 \%$ of the total utility consumption.

These issues have to be considered when designing the suggested heat integration measures. 


\section{Conclusions}

It has been shown in this paper that by site-wide collaboration it is possible to increase heat recovery and utilisation of excess heat in the chemical cluster investigated. The results from this study provide a basis to identify concrete projects which can contribute to cost and $\mathrm{CO}_{2}$ emissions savings. The study also shows the advantages of TSA as a tool to find solutions for improved energy usage by exchange of heat via the utility system on a site-wide level. Several measures to improve the energy efficiency of the chemical cluster were identified, which can save up to $122 \mathrm{MW}$ of the current external utility demand. A qualitative assessment of the suggested measures showed that $60 \mathrm{MW}(50 \%)$ of the savings can be achieved by moderate changes to the existing heat exchanger system and $110 \mathrm{MW}(92 \%)$ of the changes are technically feasible. The results of this study also indicate that there is an opportunity for increased recovery of $33 \mathrm{MW}$ of 2 bar $(\mathrm{g})$ steam from the processes, which can be delivered to other processes within the cluster.

In practice the introduction of a hot water circuit implies that process coolers have to be redesigned to use hot water instead of cooling water or air. Process heaters have to be redesigned for hot water instead of steam heating. In some cases, new equipment may be required. Hot water pipes between several plants have to be constructed as the sources and sinks of heat are spread out across the cluster.

\section{Discussion}

Limitations for integration of several plants with a common utility system:

- Different operating times resulting in the installation of back-up heating and cooling capacity is necessary

- Long distance between the plants is increasing the investment costs

- Hot water instead of steam heating results in larger area of heat exchangers, which can be expensive in congested areas

- Many heat sources and sinks making temperature regulation difficult

Recovery of process heat by the suggested measures also decreases the cooling demand. This is a very important issue and makes energy efficiency investments even more interesting for the investigated cluster as its fresh water use is restricted.

\section{Acknowledgements}

We'd like to thank all project participants for their support: Jerker Arvidsson at AGA Gas, David Ekeroth and Erik Falkeman at Akzo Nobel, Reine Spetz at Borealis, Kent Olsson, Peter Andersson and Helèn Axelsson at INEOS, Milos Pollard and Lars Lind at Perstorp and Per-Åke Franck at CIT Industriell Energianalys. Project financing was provided by the participating companies and the Swedish Energy Agency.

\section{References}

[1] Linnhoff March. The Methodology and Benefits of Total Site Pinch Analysis. 2000. <www.linnhoffmarch.com/pdfs/TotalSiteMethodology.pdf>; Accessed: 30.11.2009

[2] Matsuda K, Hirochi Y, Tatsumi H, Shire T. Applying heat integration total site based pinch technology to a large industrial area in Japan to further improve performance of highly efficient process plants. Energy 2009; 34: 1687-1692.

[3] Perry S, Klemes J, Bulatov I. Integrating waste and renewable energy to reduce the carbon footprint of locally integrated energy sectors. Energy 2008; 33: 1489-1497.

[4] Chertow MR. Uncovering" industrial symbiosis". Journal of Industrial Ecology 2007; 11: 11-30.

[5] Dhole VR, Linnhoff B. Total site targets for fuel, co-generation, emissions, and cooling. Computers \& Chemical Engineering 1993; 17: S101-S109.

[6] Raissi K. Total site integration. PhD Thesis. UMIST, Manchester, UK. 1994.

[7] Hu C, Ahmad S. Total site heat integration using the utility system. Computers \& Chemical Engineering 1994; 18: 729-742.

[8] Klemes J, Dhole VR, Raissi K, Perry SJ, Puigjaner L. Targeting and design methodology for reduction of fuel, power and CO2 on total sites. Applied Thermal Engineering 1997; 17: 993-1003. 
[9] Maréchal F, Kalitventzeff B. Energy integration of industrial sites: tools, methodology and application. Applied Thermal Engineering 1998; 18: 921-933.

[10] Marechal F, Kalitventzeff B. Targeting the integration of multi-period utility systems for site scale process integration. Applied Thermal Engineering 2003; 23: 1763-1784.

[11]Bandyopadhyay S, Varghese J, Bansal V. Targeting for cogeneration potential through total site integration. Applied Thermal Engineering 2010; 30: 6-14.

[12] Varbanov P, Klemes J. Total Sites Integrating Renewables With Extended Heat Transfer and Recovery. Heat Transfer Engineering 2010; 31: 733-741.

[13]Fodor Z, Varbanov PS, Klemes J. Total Site Targeting Accounting for Individual Process Heat Transfer Characteristics. Chemical Engineering Transactions, 2010, 21: 49-54.

[14] Klemes J, Friedler F, Bulatov I, Varbanov P. Sustainability in the Process Industry: Integration and Optimization. 1st ed. New York: McGraw-Hill Professional; 2010: 96-103.

[15] Brown S. The drive for refinery energy efficiency. Petroleum Technology Quaterly 1999;: 45-55.

[16] Bagajewicz M, Rodera $\mathrm{H}$. On the use of heat belts for energy integration across many plants in the total site. The Canadian Journal of Chemical Engineering 2001; 79: 633-642.

[17]Zhu FXX, Vaideeswaran L. Recent research development of process integration in analysis and optimisation of energy systems. Applied Thermal Engineering 2000; 20: 1381-1392.

[18] Fagernäs L, Brammer L, Wilén C, Lauer M, Verhoeff F. Drying of biomass for second generation synfuel production, Biomass and Bioenergy 2010; 34: 1267-1277.

[19] Desai NB, Bandyopadhyay S, Process integration of organic Rankine cycle, Energy 2009; 34: 16741686. 